\title{
Characterisation of glass fibres used in automotive industry for SMC body panels
}

\author{
V. Feuillade ${ }^{\text {a }}$, A. Bergeret ${ }^{\text {a }}$, J.-C. Quantin ${ }^{\mathrm{a}, *}$, A. Crespy ${ }^{\mathrm{b}}$ \\ a Ecole des Mines d'Alès, Centre des Matériaux de Grande Diffusion, 6 avenue de Clavières, 30319 Alès Cedex, France \\ b Universitéde Toulon et du Var, Bâtiment R118, BP 132, 83957 La Garde Cedex, France
}

\begin{abstract}
Advances in surface quality and a better understanding of the formation mechanisms of surface defects are required for SMC applications as body panels in the automotive industry. This study is focused on the influence of the material formulation and SMC process on the surface quality, which is probably conditioned by the interactions between the paste and the fibres. The main parameters are: (i) the amount of sizing applied on fibres, (ii) the type of antistatic agent and its deposit method and (iii) the type of film former. The approach based on surface energy evaluations seems to be a useful tool to facilitate the prediction of the surface quality without any moulding.
\end{abstract}

Keywords: A. Glass fibres; A. Moulding compounds

\section{Introduction}

Sheet Moulding Compound is a thermosetting material that consists of an unsaturated polyester resin thickened with $\mathrm{MgO}$, a particulate filler $\left(\mathrm{CaCO}_{3}\right)$ and other additives and reinforced by random in-plane orientation glass fibres (bundles) $25 \mathrm{~mm}$ length. The use of SMC in automotive industry as exterior body panels is increasing because of its high strength/weight ratio and good mechanical and ultimate properties. But the major drawback is the increasing presence of defects on the surface of SMC panels as production rates are raised. Various kinds of defects have been listed by automotive suppliers such as (i) pinholes $(<1 \mathrm{~mm})$ and craters $(>1 \mathrm{~mm})$ resulting from a limited creep of the resin in the mould, because of a local agglomeration of $\mathrm{CaCO}_{3}$ particles in the case of the pinholes and because of a low spreading ability of the lubricant agent in the case of craters, (ii) bubbles (from $1 \mathrm{~mm}$ to $1 \mathrm{~cm}$ ) due to the presence of entrapped air or volatile styrene that gener-

\footnotetext{
* Corresponding author. Tel.: +33 (0)4 667853 46; fax: +33 (0)4 6678 5365.

E-mail address: jean-christophe.quantin@ema.fr (J.-C. Quantin).
}

ate voids just under the SMC panel surface and (iii) surface waviness resulting from resin shrinkage and/or local variations of the fibre distribution. A very few literature dealt with the parameters that influence the surface quality of SMC panels excluding processing parameters (coverage [1], moulding temperatures [2], etc.) and fibre distribution [3]. Nevertheless, it may be obvious that a supplementary parameter must be taken into account which is the effectiveness of the fibre impregnation - or the fibre ability to be wetted by the resin-during the impregnation step before the resin maturation and the moulding. Indeed an incomplete impregnation or wetting of the fibres by the polyester resin may result in the formation of voids because of a slow and heterogeneous capillary spreading of the resin within the space between the fibres inside the bundles. The origin of a low fibre impregnation is mainly due to a low thermodynamical adsorption of the resin on the glass surface, therefore to a low wettability of the fibre. It can be assumed that the further phenomena of macromolecular chain diffusion, of electrostatic interactions and of formation of chemical bondings will be induced by the efficiency of the fibre wetting. Therefore according to Dupré's equation [4] the determination of the dispersive and polar 
components of the surface free energy of the fibres on one hand, and of the resin on the other hand, may be a way to evaluate the fibre/resin impregnation. It is well known that (i) an optimal wetting of the fibres by the polyester resin is obtained if the surface free energy of the fibre is superior to those of the resin, and that (ii) an optimal adhesion between the fibres and the polyester resin is obtained if the dispersive and polar components of the fibre are close to those of the resin. In this approach, it can be noticed that the adhesion is referring to liquid/solid adhesion models (macromolecular chain diffusion model, chemical model, electrostatic model, etc.) and not to classical adhesion tests that measure the adhesion strength in the solid state. The impregnation ability should be then influenced by the sizing type applied on glass fibres and by the resin composition and thus by the interfacial adhesion [5-11]. Most of the researches were focused on the influence of silane coupling agents on polymer/glass interactions $[6,12-16]$. However, commercial glass fibre sizings are multi-component mixtures in which the silane represents only a small fraction of the total mass deposited on the glass surface. So, it appears interesting to focus the study on commercial glass fibres to assess the principal parameters. The same analysis can be carried out for the polyester resin [17-22]. Indeed a lot of studies were achieved for simplified resin formulations consisting of unsaturated polyester resin, styrene and a low profile (less than 0.05\% shrinkage) additive.

In the present work, the influence of the sizing chemical composition on the fibre wetting ability by the unsaturated polyester resin before the curing reaction was studied and its effect on the surface quality of SMC panels was investigated through an identification of the film former and the antistatic agent used for the fibre sizings.

\section{Materials and techniques}

\subsection{Materials}

Two commercially sized glass fibres (fibres A and B with main characteristics given in Table 1) provided by Saint Gobain Vetrotex International (Chambéry, France). In both sizing compositions, the silane coupling agent is considered as a constant component that did not influence the wetting characteristics of the sized fibre. In fact, it is well known that the silane is mainly located at the surface of the fibre as the other components (film formers, antistatic agents). A SMC polyester paste (Ashland Polyester, Italy) with a confidential formulation was used to investigate, on

Table 1

Characteristics of the fibres (loss on ignition represents the sizing content)

\begin{tabular}{llll}
\hline Fibre & Tex $(\mathrm{g} / \mathrm{km})$ & Diameter $(\mu \mathrm{m})$ & $\begin{array}{l}\text { Loss on } \\
\text { ignition }(\%)\end{array}$ \\
\hline A & 2400 & 15.6 & 1.20 \\
B & 2200 & 14 & 1.78 \\
\hline
\end{tabular}

the one hand, the effects of glass sizings on the fibre wetting ability by the matrix and, on the other hand, on the fibre/ matrix adhesion and finally on the surface quality.

\subsection{Techniques}

\subsubsection{Extraction procedures}

The soluble fractions of the glass fibre coating were measured according to ISO 11667 standard [23]. A minimum of three samples was used in each determination. Two solvents were used for extractions: (i) acetone as a reference and (ii) styrene which is the major component of the SMC polyester resin. Soxhlet extractions and extractions at room temperature (according to ISO 11667 specification [23]) and at $60^{\circ} \mathrm{C}$ were carried out for durations between 1 and $24 \mathrm{~h}$. The sizing solubility percentages were determined by

$S(\%)=\frac{m_{0}-m_{1}}{m_{0}-m_{2}} \times 100$,

where $m_{0}$ and $m_{1}$ are the weights of the fibres, respectively, before and after extraction and $m_{2}$ the weight of fibres after calcination at $625 \pm 20^{\circ} \mathrm{C}$ during $30 \pm 5 \mathrm{~min}$.

\subsubsection{FTIR}

Fourier transform infra-red (FTIR) spectra were recorded between 4000 and $400 \mathrm{~cm}^{-1}$ using a BRUKER IFS66 set-up in ATR mode (32 scans, resolution of $4 \mathrm{~cm}^{-1}$ ) on the various fractions obtained after extraction. As preliminary FTIR measurements performed on the soluble fractions obtained after an extraction in styrene at 25 and $60{ }^{\circ} \mathrm{C}$ have given evidence of the presence of polystyrene, only the solubility percentage in styrene has been determined and no FTIR analyses of the solubilized components.

\subsubsection{Pyrolysis/GC/MS}

Samples $(2 \mathrm{mg})$ of the fibres were pyrolysed using a SGE-Pyrojector Mk II at $800^{\circ} \mathrm{C}$ (Catalyse, Marseille, France). The evolved components were separated by using a Hewlett Packard 6890 gas chromatograph and analysed by means of Hewlett Packard 5973N mass spectrometer.

\subsection{4. $X P S$}

X-ray photoelectron spectroscopy (XPS) measurements on glass fibres surfaces were carried out with a XSAM 300 instrument (Saint Gobain Recherche, Aubervilliers, France). $\mathrm{Mg} \mathrm{K} \alpha$ line was used for samples excitation. The input lens of the photoelectron analyser was configured in such a way that a sample area of $1 \mathrm{~cm}^{2}$ was probed and so that the surface composition determined represents the average of many fibres. Quantitative data are recorded from high-resolution scanning with a 20 and $40 \mathrm{eV}$ pass energy (intensity $10 \mathrm{~mA}$, tension $10 \mathrm{kV}$ ). Two specimens were used for each analysis. The analysis depth is about $50 \AA$ A. 


\subsubsection{Static SIMS (SSIMS) and dynamic}

SIMS (DSIMS)

SSIMS and DSIMS experiments were performed using a Tof-SIMS IV ion microscope (Saint Gobain Recherche, Aubervilliers, France) with a $\mathrm{Cs}^{+}$ion source and a mass resolution of $10,000 \mathrm{~m} / z$. The lateral and depth resolutions range, respectively, from about 0.1 to $0.5 \mu \mathrm{m}$ and from about 1 to $5 \mathrm{~nm}$. A Cs ${ }^{+}$source with $E=3 \mathrm{kV}, I=25 \mathrm{nA}$ and a $\mathrm{Ga}^{+}$source with $E=15 \mathrm{kV}, I=0.5 \mathrm{pA}$ (for the profiles), $E=15 \mathrm{kV}, \quad I=1 \mathrm{pA}$ (for the spectrum), and $E=25 \mathrm{kV}, I=0.5 \mathrm{pA}$ (for the images), were used, respectively, for the blasting gun and the analysis gun. The analysis chamber pressure was around $10^{-4} \mathrm{~Pa}$ and the analysis depth about $20 \AA$.

\subsubsection{Contact angle measurements}

Surface properties and therefore contact angle measurements of the sized glass fibres were performed using a KSV LPR902 which is a powder wetting instrument (KSV Instruments). This experimental technique is based on a measurement of the volume of liquid absorbed by the powder by capillarity (here a fibre network) versus time. The fibres were cut to $9 \mathrm{~mm}$ length and samples of $7 \mathrm{~g}$ were packed into a glass cylinder ( $15 \mathrm{~mm}$ diameter and $30 \mathrm{~mm}$ high).

The contact angle, $\theta$, was then determined using Washburn's equation (2) [24] which defines the flow of a liquid through a capillary. When a porous solid is in contact with a liquid, the liquid rise within the solid pores is governed by

$t=\left[\frac{\eta}{C \cdot \gamma_{\mathrm{L}} \cdot \cos \theta}\right] V^{2}$,

where $t$ is the time after contact, $\eta$ the liquid viscosity, $C$ a constant depending on the analysed material and not on the used liquid, $\gamma_{L}$ the surface free energy of the liquid, $\theta$ the contact angle and $V$ the liquid volume absorbed on the solid. The constant $C$ depends on the porosity of the particles - here the glass fibres - and on the packing of the fibres. In our case no porosity of the fibres and a good reproducibility of the packing can be assumed.

The variations of the time versus $V^{2}$ is a straight line with a slope $A=\frac{\eta}{C \cdot \eta_{\mathrm{L}} \cdot \cos \theta}$. As the liquid viscosity and the liquid surface free energy are known parameters, the contact angle $\theta$ and the material constant $C$ can be determined. In order to determine the $C$ value, one measurement can be provided when the contact angle is presumed to be equal to zero, what is the case for liquids with little surface tension such as $n$-hexane $\left(\gamma_{\mathrm{L}}=18.4 \mathrm{~mJ} / \mathrm{m}^{2}[25,26]\right)$. The material constant $C$ is determined:

$C=\frac{\eta}{A \cdot \gamma_{\mathrm{L}}}$.

The $C$ value being known, the same experiments can be carried then out with other liquids that wet the solid in order to calculate the contact angle.

Contact angle measurements of the SMC polyester resin were performed using a DIGIDROP apparatus (GBX Instruments) with an automatic system for the liquid drop- let formation on the SMC polyester resin. In this case, the SMC resin is considered as a solid. The wetting liquids used for contact angle measurements, during the test, were $n$ hexane, water, toluene and ethylene glycol.

In order to determine the dispersive and the polar components of the surface free energy, on the one hand, of the sized glass fibres, and on the other hand, of the SMC resin, the geometric approach proposed by Owens et al. has been used [27,28]:

$\gamma_{\mathrm{L}}(1+\cos \theta)=2 \cdot \sqrt{\gamma_{\mathrm{S}}^{\mathrm{D}} \cdot \gamma_{\mathrm{L}}^{\mathrm{D}}}+2 \cdot \sqrt{\gamma_{\mathrm{S}}^{\mathrm{P}} \cdot \gamma_{\mathrm{L}}^{\mathrm{P}}}$,

where the subscripts $\mathrm{L}$ and $\mathrm{S}$ are related, respectively, to the liquid and the solid states, and $\mathrm{D}$ and $\mathrm{P}$ to the dispersive and polar characters.

Eq. (4) can be written as follows:

$y=m x+b$,

where

$x=\sqrt{\frac{\gamma_{\mathrm{L}}-\gamma_{\mathrm{L}}^{\mathrm{D}}}{\gamma_{\mathrm{L}}^{\mathrm{D}}}}$,

$y=\frac{1+\cos \theta}{2} \frac{\gamma_{\mathrm{L}}}{\sqrt{\gamma_{\mathrm{L}}^{\mathrm{D}}}}$,

$m=\sqrt{\gamma_{\mathrm{S}}^{\mathrm{P}}}$

$b=\sqrt{\gamma_{\mathrm{S}}^{\mathrm{D}}}$,

$\gamma_{L}, \gamma_{L}^{\mathrm{D}}, \gamma_{\mathrm{L}}^{\mathrm{P}}$ values are known parameters for all the wetting liquids. As the solid surface contact angle can be measured, the dispersive and polar components of the solid can be determined from $y=m x+b$ equation which is obtained by a linear regression.

\subsubsection{Moulding parameters}

The SMC pre-pregs used in the present investigation were provided by Saint-Gobain Vetrotex Italia. The glass fibres used in SMC formulations were $25 \mathrm{~mm}$ length and the weight ratio was about $28 \%$. The moulded panels were obtained through a $400 \mathrm{t}$ compression machine (Rhonalp System) provided by Compositec (Le Bourget du Lac, France). The mould dimensions were $500 \times 500 \mathrm{~mm}^{2}$. The initial SMC charge pattern was placed to cover $30 \%$ of the mould surface to make a final panel with a thickness of $2 \mathrm{~mm}$. The mould was equipped with a mirror polish punch. The matrix surface and the punch surface temperatures were, respectively, $150 \pm 1{ }^{\circ} \mathrm{C}$ and $145 \pm 1^{\circ} \mathrm{C}$. The moulding cycle was as follows: closure speed: $300 \mathrm{~mm} \mathrm{~s}^{-1}$, work speed: $7 \mathrm{~mm} \mathrm{~s}^{-1}$, hold pressure: 70 bars, cycle time: $100 \mathrm{~s}$.

Once the SMC panels were moulded, the surface finish was determined. For this evaluation, a Diffracto Sight AS-2 apparatus (Saint-Gobain Vetrotex International, Besana, Italy) was used to detect the waviness. The measure is based on an optical method: a white light beam is projected on the panel, reflected on a mirror opposite to 
the light source and returned back to the panel where it is recorded by a camera. This image is compared to a reference panel and a Diffracto index is given. A good surface aspect corresponds to a low Diffracto index [1]. The other defects like pinholes, craters and bubbles were evaluated by human visual counting.

\section{Results and discussion}

\subsection{Surface quality of the SMC panels moulded with the fibres $A$ and $B$}

Surface finish and the number of defects are presented in Table 2. It can be observed that the SMC panel moulded with the fibre A presents a lower Diffracto index and therefore a better surface finish than the SMC panel moulded with the fibre $\mathrm{B}$ despite of a greater number of defects. A good surface quality may therefore be the result of a compromise between a low Diffracto index and a low number of defects. In order to achieve this compromise, the study will be focused on the determination of all parameters that may affect this surface quality and especially parameters linked to the fibre coating. As the fibres A and B present equivalent physical parameters (type of glass, diameter, etc.), a first part of this paper will be to perform a deep analysis of the fibre sizing.

\subsection{XPS analysis of the fibre surface}

XPS analysis should give informations about the first $50 \AA$ of the surface. This analysis was performed on sized fibres to obtain a semi-quantitative composition of the surface samples. The following energy levels were studied: $\mathrm{C}_{1 \mathrm{~s}}$, $\mathrm{O}_{1 \mathrm{~s}}, \mathrm{Si}_{2 \mathrm{p}}, \mathrm{N}_{1 \mathrm{~s}}, \mathrm{Cl}_{2 \mathrm{p}}, \mathrm{S}_{2 \mathrm{p}}$ and $\mathrm{Ca}_{2 \mathrm{p}}$. Spectra were recorded for energy of $20 \mathrm{eV}$ and an incidence angle of 30 degrees. Results are presented in Table 3.

As the ratio C/Si is superior to 10 (fibre A: $34.36 \pm 12.06$ and fibre $\mathrm{B}: 32.87 \pm 9.92$ ), the atom $\mathrm{Si}$ should be related to silane coupling agents contained in the sizing and not to the glass itself [29-32]. Moreover the $\mathrm{C} / \mathrm{Si}$ ratio may give informations about the sizing distribution on the fibres [6].

Table 2

Diffracto index and number of defects of the SMC panels $\left(500 \times 500 \mathrm{~mm}^{2}\right.$ area)

\begin{tabular}{lllll}
\hline Fibre & Diffracto index & Pinholes & Craters & Bubbles \\
\hline A & $105.9 \pm 11.0$ & $1.4 \pm 2.1$ & $10.8 \pm 5.8$ & 0 \\
B & $166.4 \pm 12.5$ & 0 & $1 \pm 1.1$ & 0 \\
\hline
\end{tabular}

Results show that the distribution is similar for both fibres. But, as this ratio $\mathrm{C} / \mathrm{Si}$ is less than 50 , distribution of the sizing on the fibres may be heterogeneous and sometimes discontinuous [6]. This result was confirmed by SEM (scanning electron microscopy) observations performed on the glass fibre surface and by the presence of Ca (XPS measurements).

The $\mathrm{N}_{1 \mathrm{~s}}$ peak can be curve-fitted with two components: (i) the first around $399.5 \mathrm{eV}$ compatible with the presence of secondary amino groups [33], (ii) the second around

Table 4

Peak identification for SSIMS spectra on fibres A and B

\begin{tabular}{|c|c|}
\hline $\operatorname{Mass}(\mathrm{m} / \mathrm{z})$ & Composition \\
\hline \multicolumn{2}{|c|}{ Positive spectra } \\
\hline 15 & $\mathrm{CH}_{3}^{+}$(fibres A and $\mathrm{B}$ ) \\
\hline 27 & $\mathrm{C}_{2} \mathrm{H}_{3}^{+}$(fibres $\mathrm{A}$ and $\mathrm{B}$ ) \\
\hline 28 & $\mathrm{C}_{2} \mathrm{H}_{5}^{+}$(fibres $\mathrm{A}$ and $\mathrm{B}$ ) \\
\hline 29 & $\mathrm{Si}^{+} / \mathrm{C}_{2} \mathrm{H}_{4}^{+}$(fibres $\mathrm{A}$ and $\mathrm{B}$ ) \\
\hline 39 & $\mathrm{~K}^{+}($fibres $\mathrm{A}$ and $\mathrm{B})$ \\
\hline 41 & $\mathrm{C}_{3} \mathrm{H}_{5}^{+}$(fibres $\mathrm{A}$ and $\mathrm{B}$ ) \\
\hline 43 & $\mathrm{C}_{3} \mathrm{H}_{7}^{+}$(fibres $\mathrm{A}$ and $\left.\mathrm{B}\right)$ \\
\hline 55 & $\mathrm{C}_{4} \mathrm{H}_{7}^{+}$(fibres $\mathrm{A}$ and $\left.\mathrm{B}\right)$ \\
\hline 58 & $\mathrm{C}_{4} \mathrm{H}_{11}^{+} / \mathrm{C}_{3} \mathrm{H}_{8} \mathrm{~N}^{+}$(fibres $\mathrm{A}$ and $\mathrm{B}$ ) \\
\hline 59 & $\mathrm{C}_{3} \mathrm{H}_{8} \mathrm{~N}^{+}$(fibres $\mathrm{A}$ and $\mathrm{B}$ ) \\
\hline 69 & $\mathrm{C}_{5} \mathrm{H}_{9}^{+}$(fibres $\mathrm{A}$ and $\mathrm{B}$ ) \\
\hline 114 & $\mathrm{C}_{7} \mathrm{H}_{16} \mathrm{~N}^{+}$(fibre $\left.\mathrm{A}\right)$ \\
\hline 128 & $\mathrm{C}_{8} \mathrm{H}_{18} \mathrm{~N}^{+}$(fibre $\left.\mathrm{A}\right)$ \\
\hline 142 & $\mathrm{C}_{9} \mathrm{H}_{20} \mathrm{~N}^{+}($fibre $\mathrm{A})$ \\
\hline 156 & $\mathrm{C}_{10} \mathrm{H}_{22} \mathrm{~N}^{+}$(fibre A) \\
\hline 170 & $\mathrm{C}_{11} \mathrm{H}_{24} \mathrm{~N}^{+}$(fibre $\mathrm{A}$ ) \\
\hline 184 & $\mathrm{C}_{12} \mathrm{H}_{26} \mathrm{~N}^{+}$(fibre $\mathrm{A}$ ) \\
\hline 200 & $\mathrm{C}_{13} \mathrm{H}_{30} \mathrm{~N}^{+}$(fibre $\mathrm{A}$ ) \\
\hline 228 & $\mathrm{C}_{15} \mathrm{H}_{34} \mathrm{~N}^{+}$(fibre $\mathrm{A}$ ) \\
\hline 360 & $\mathrm{C}_{26} \mathrm{H}_{48}^{+}$(fibre $\left.\mathrm{B}\right)$ \\
\hline 388 & $\mathrm{C}_{28} \mathrm{H}_{52}^{+\circ}$ (fibre B) \\
\hline \multicolumn{2}{|c|}{ Negative spectra } \\
\hline 13 & $\mathrm{CH}^{-}$(fibres A and B) \\
\hline 16 & $\mathrm{O}^{-}($fibres $\mathrm{A}$ and $\mathrm{B})$ \\
\hline 17 & $\mathrm{OH}^{-}($fibres $\mathrm{A}$ and $\mathrm{B})$ \\
\hline 25 & $\mathrm{C}_{2} \mathrm{H}^{-}$(fibres $\mathrm{A}$ and $\mathrm{B}$ ) \\
\hline 32 & $\mathrm{~S}^{-}($fibre $\mathrm{B})$ \\
\hline 35 & $\mathrm{Cl}^{-}$(fibre $\left.\mathrm{A}\right)$ \\
\hline 60 & $\mathrm{SiO}_{2}^{-} / \mathrm{SiO}_{2} \mathrm{H}^{-}($fibre $\mathrm{A})$ \\
\hline 80 & $\mathrm{SO}_{3}^{-}$(fibre B) \\
\hline 97 & $\mathrm{HSO}_{4}^{-}$(fibre B) \\
\hline 125 & $\mathrm{C}_{2} \mathrm{H}_{5} \mathrm{SO}_{4}^{-}$(fibre B) \\
\hline 181 & $\mathrm{Si}_{3} \mathrm{O}_{6} \mathrm{H}^{-}$(fibres $\mathrm{A}$ and $\mathrm{B}$ ) \\
\hline 185 & $\mathrm{C}_{5} \mathrm{H}_{5} \mathrm{Si}_{2} \mathrm{O}_{4}^{-}$(fibres $\mathrm{A}$ and $\mathrm{B}$ ) \\
\hline 197 & $\mathrm{Si}_{3} \mathrm{O}_{7} \mathrm{H}^{-}$(fibres $\mathrm{A}$ and $\mathrm{B}$ ) \\
\hline 223 & $\mathrm{C}_{5} \mathrm{H}_{15} \mathrm{Si}_{3} \mathrm{O}_{4}^{-}$(fibres A and $\mathrm{B}$ ) \\
\hline
\end{tabular}

Table 3

Surface atomic composition of the fibres A and B

\begin{tabular}{|c|c|c|c|c|c|c|c|c|c|c|}
\hline \multirow[t]{2}{*}{ Fibre } & \multicolumn{7}{|c|}{ Atomic percentage } & \multicolumn{3}{|l|}{ Ratio } \\
\hline & $\mathrm{C}$ & $\mathrm{O}$ & $\mathrm{N}$ & $\mathrm{Cl}$ & $\mathrm{Si}$ & S & $\mathrm{Ca}$ & $\mathrm{C} / \mathrm{Si}$ & $\mathrm{C}-\mathrm{O} / \mathrm{C}-\mathrm{H}$ & $\mathrm{O}-\mathrm{C}=\mathrm{O} / \mathrm{C}-\mathrm{H}$ \\
\hline A & $79.50 \pm 2.83$ & $15.30 \pm 3.11$ & $1.75 \pm 0.64$ & $0.80 \pm 0.57$ & $2.45 \pm 0.78$ & & $0.45 \pm 0.07$ & $34.36 \pm 12.06$ & $0.29 \pm 0.06$ & $0.06 \pm 0.02$ \\
\hline B & $72.10 \pm 0.42$ & $23.65 \pm 0.64$ & $0.95 \pm 0.21$ & & $2.30 \pm 0.71$ & $0.65 \pm 0.21$ & $0.33 \pm 0.05$ & $32.87 \pm 9.92$ & $0.53 \pm 0.05$ & $0.14 \pm 0.00$ \\
\hline
\end{tabular}


$402.2 \mathrm{eV}$ compatible with $\mathrm{NH}_{3}^{+}$[33] resulting from the reaction between amino groups of the silane component and $\mathrm{Si}-\mathrm{OH}$ groups present at the glass surface. Data showed that a greater number of secondary amino groups are present on the fibre A surface than on the fibre B surface. In the case of the fibre A, the presence of chlorine has been detected. This may be related to the presence of an ammonium chloride component commonly used as antistatic agents for glass fibres. In the case of the fibre B, the presence of sulphur has been revealed. The binding energy of $\mathrm{S}_{2 \mathrm{p}}(170.5 \mathrm{eV})$ let us suppose that this element is present in a sulphate component. The $\mathrm{C}_{1 \mathrm{~s}}$ spectra can be curve-fitted with three components: (i) a main component at a binding energy of $284.6 \mathrm{eV}$ corresponding to $\mathrm{C}-\mathrm{H}$ [13], (ii) a component at a binding energy of $286.5 \mathrm{eV}$ corresponding to functional groups such as $\mathrm{C}-\mathrm{O}$ and $\mathrm{C}-\mathrm{N}$ [13], and (iii) a component at a binding energy of $288.7 \mathrm{eV}$ corresponding to carboxylic groups $(\mathrm{O}-\mathrm{C}=\mathrm{O})$ [13]. From the previous hypothesis, the absolute and relative percentages of these different components have also been determined. Results show that $\mathrm{C}-\mathrm{O} / \mathrm{C}-\mathrm{H}$ and $\mathrm{O}-\mathrm{C}=\mathrm{O} / \mathrm{C}-\mathrm{H}$ ratios are twice as high for fibre $\mathrm{B}$ than for fibre $\mathrm{A}$.

\subsection{Static SIMS analysis of the fibre surface}

To obtain more informations about chlorine and sulphur components, a static SIMS analysis was carried out on both fibres. From positive and negative spectra, the fibre composition was determined [13,34] (Table 4). For fibre A, peaks at $m / z=58,114,128,142,156,170,184$, 200 and 228 in the positive spectra and the peak at $\mathrm{m} /$ $z=35$ in the negative spectra may indicate the presence of dodecyltrimethylammonium chloride used as antistatic agent. The negative spectra of the fibre B should be related to a diethylsulphate. A comparison investigated with a standard ammonium diethylsulphate commonly used for glass fibre manufacturing has confirmed this last result.

\subsection{Solubility of the glass fibre sizing}

Extraction procedures were previously described (Section 2.2.1) and were carried out both in acetone (reference) and in styrene according to the impregnation conditions [35]. Preliminary tests have shown that the chemical nature of the soluble fractions of the sizing is independent of the extraction temperature $\left(25\right.$ or $\left.60^{\circ} \mathrm{C}\right)$ as it can be observed on FTIR spectra (Fig. 1).

The results obtained from acetone and styrene extractions show that the sizing of the fibre $\mathrm{A}$ is more soluble than the sizing of the fibre B (Figs. 2 and 3) and that for each fibre; the solubility remains constant after about $6 \mathrm{~h}$.

The soluble fractions in acetone were characterised using FTIR (Fig. 1). Identifications of the FTIR peaks are detailed in Table 5 and show that both sizing soluble fractions are based on polyvinylacetate (PVAc) with characteristic peaks located for example for the fibre A at 1727,

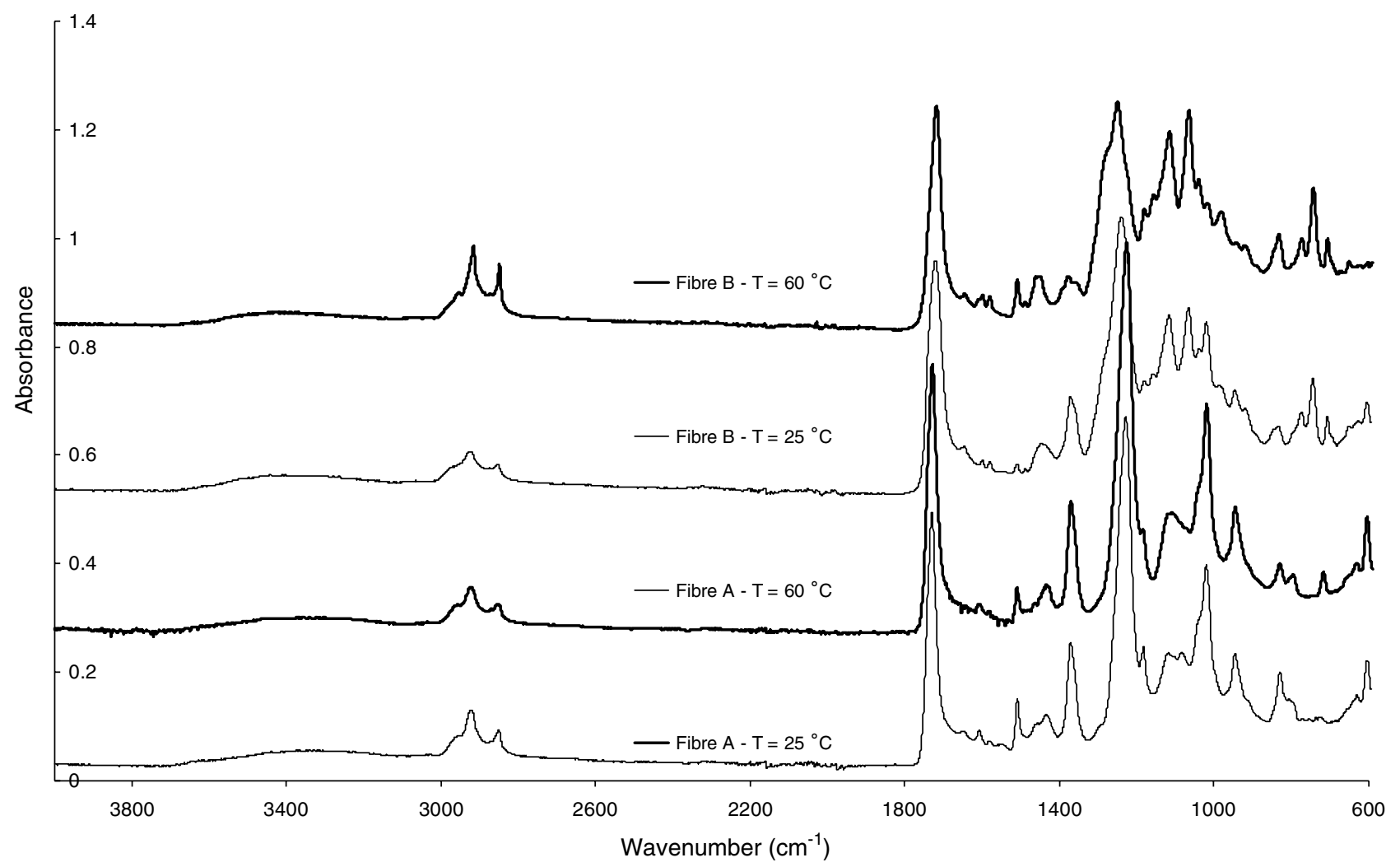

Fig. 1. FTIR spectra of sizing soluble fraction in acetone for the fibres A and B at $T=25$ and $60{ }^{\circ} \mathrm{C}$. 
$1372,1224,1017$ and $947 \mathrm{~cm}^{-1}$. This result seems to be in good agreement with Pyrolysis/GC/MS data (Table 6) that show the presence of acetic acid, which is the main degradation component of PVAc. Differences between both spectra can be observed because of the presence of specific peaks for fibre B located on one hand at 1280, 1120, 1120 and $743 \mathrm{~cm}^{-1}$ and that may be related to phthalate groups and on the other hand at 1636 and $1064 \mathrm{~cm}^{-1}$ that may be related to acid functions. This result has been confirmed through Pyrolysis/GC/MS experiments that revealed the presence of a phthalic anhydride compound that is commonly used in polyester formulations. The acid functions result from the hydrolysis of this anhydride.

The insoluble components were analyzed by XPS (after an extraction time of $6 \mathrm{~h}$ ) and DSIMS was performed on the fibre surface.

\subsection{XPS analysis of fibres $A$ and $B$ after acetone and styrene extractions}

After acetone and styrene extractions, a decrease in $\mathrm{C}$ and $\mathrm{N}$ atomic percentages and an increase in $\mathrm{O}$ and $\mathrm{Si}$ ones (Fig. 4) were observed. Moreover, results show that the antistatic agents have been removed after extractions because of the decrease in $\mathrm{Cl}$ atomic percentage for fibre $\mathrm{A}$ and in $\mathrm{S}$ atomic percentage for fibre B. As it remains difficult to determine the distribution of the antistatic agent, DSIMS analyses were also performed.

\subsection{DSIMS analysis in the thickness sizing}

XPS analyses have shown that $\mathrm{Cl}$ and $\mathrm{S}$ atoms were present on the sized fibres and not on the fibres after

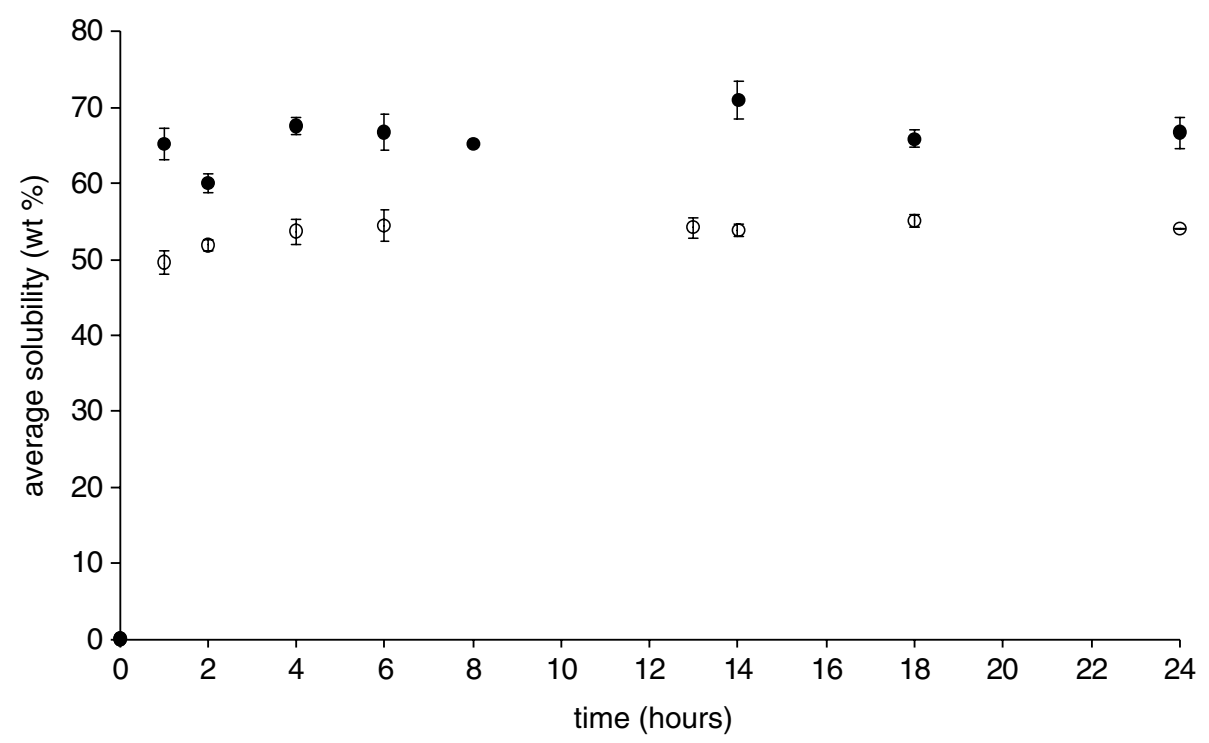

Fig. 2. Kinetics of sizing solubility in acetone ( fibre A, $\bigcirc$ fibre B).

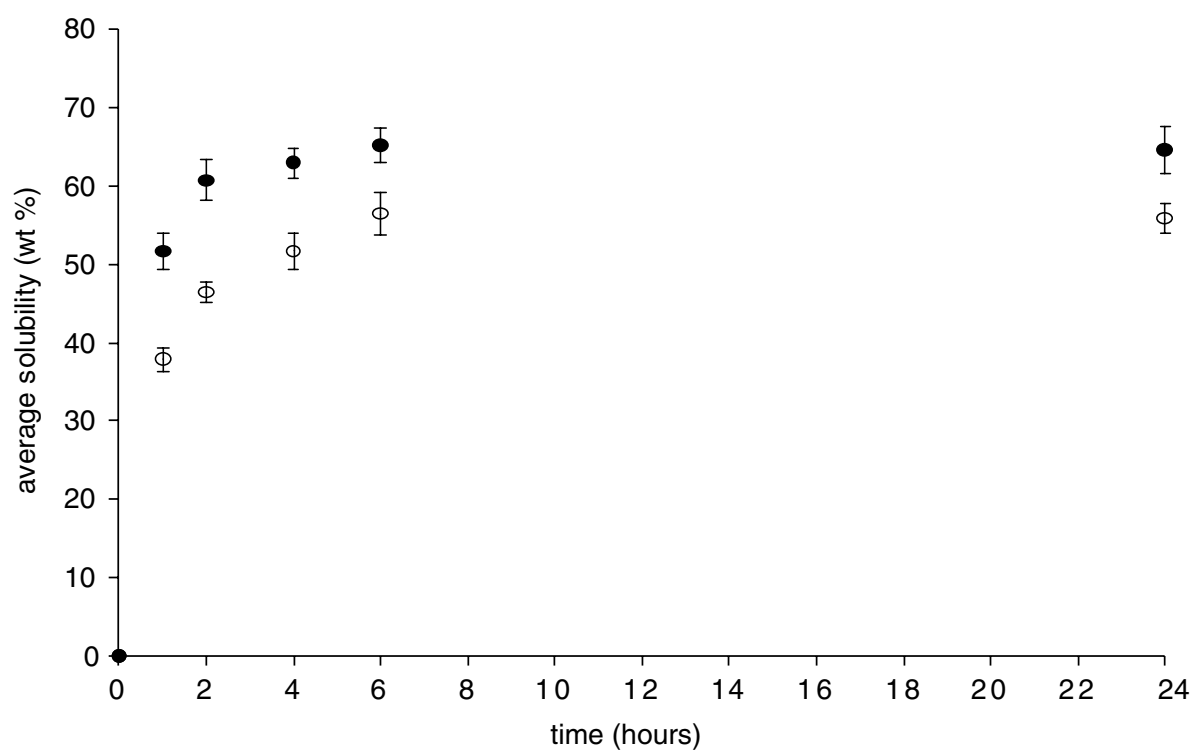

Fig. 3. Kinetics of sizing solubility in styrene ( $\rightarrow$ fibre A, $\bigcirc$ fibre B). 
Table 5

FTIR peaks attribution of the sizing soluble fractions of the fibres A and B

\begin{tabular}{ll}
\hline Peak $\left(\mathrm{cm}^{-1}\right)$ & Attribution \\
\hline Fibre $A$ & \\
$2948,2916,2846$ & $0 \mathrm{C}-\mathrm{H}$ aliphatic \\
1727 & $0 \mathrm{C}=\mathrm{O}$ acetate \\
$1601,1573,1508$ & $0 \mathrm{C}=\mathrm{C}$ aromatic \\
1372 & $\delta \mathrm{CH}$ de $\mathrm{CH}_{3}(\mathrm{C}=\mathrm{O})$ \\
1224 & $0 \mathrm{C}-\mathrm{C}-\mathrm{O}$ acetate \\
1101 & $\delta \mathrm{C}-\mathrm{H}$ aromatic \\
1017 & $\delta \mathrm{C}-\mathrm{C}-\mathrm{O}$ acetate \\
947 & $\delta \mathrm{C}=\mathrm{C}$ vinyl \\
Fibre $B$ & \\
3445 & $0 \mathrm{O}-\mathrm{H}$ acid or alcohol \\
$2964,2919,2848$ & $0 \mathrm{C}-\mathrm{H}$ aliphatic \\
1718 & $0 \mathrm{C}=\mathrm{O}$ acetate \\
1636 & $0 \mathrm{C}=\mathrm{O}$ acid \\
$1595,1577,1506$ & $0 \mathrm{C}=\mathrm{C}$ aromatic \\
1373 & $\delta \mathrm{CH}$ de $\mathrm{CH} \mathrm{H}_{3}(\mathrm{C}=\mathrm{O})$ \\
1280 & $0 \mathrm{C}-\mathrm{O}$ phthalate \\
1237 & $0 \mathrm{C}-\mathrm{C}-\mathrm{O}$ acetate + acid \\
1120 & $0 \mathrm{C}-\mathrm{O}$ phthalate \\
1113 & $\delta \mathrm{C}-\mathrm{HC}$ aromatic \\
1064 & $\delta \mathrm{C}-\mathrm{C}-\mathrm{O}$ acid \\
1018 & $\delta \mathrm{C}-\mathrm{C}-\mathrm{O}$ acetate \\
979 & $\delta \mathrm{C}-\mathrm{H}$ aromatic \\
943 & $\delta \mathrm{C}=\mathrm{C}$ vinyl \\
743 & $\delta \mathrm{C}=\mathrm{O}$ phthalate \\
\hline &
\end{tabular}

Table 6

Main components evolved through Pyrolysis/GC/MS results

\begin{tabular}{ll}
\hline Area $(\%)$ & Compound \\
\hline Fibre $A$ & \\
10.51 & Acetic acid \\
0.88 & Acetophenone \\
Fibre $B$ & \\
7.57 & Acetic acid \\
6.65 & Phthalic anhydride \\
2.10 & Acetic acid, phenyl ester \\
1.24 & Acetophenone \\
\hline
\end{tabular}

extractions. Also, the distribution of these atoms in depth at the fibre surface was studied through DSIMS experiments performed on a $100 \times 100 \mu \mathrm{m}^{2}$ area (Figs. 5 and 6).

Signals of $\mathrm{S}$ and $\mathrm{Cl}$ atoms, respectively, on the fibres $\mathrm{B}$ and $\mathrm{A}$ surfaces and of $\mathrm{C}$ atom decrease from the surface of the sizing to the outer surface of the fibre as signals of $\mathrm{O}$ and $\mathrm{Si}$ atoms increase. It can be noticed that $\mathrm{CN}^{-}$ions signal was studied instead of $\mathrm{N}^{+}$or $\mathrm{N}^{-}$ions signals because of their higher intensities.

From DSIMS experiments which analyse the first $20 \mathrm{~nm}$ sizing layers the nearest to the surface, it can be assumed that antistatic agents may diffuse through the thickness of the sizing.

\subsection{Contact angle and surface free energy analyses}

Results obtained for both glass fibres and SMC polyester resin are listed in Table 7. The value of the
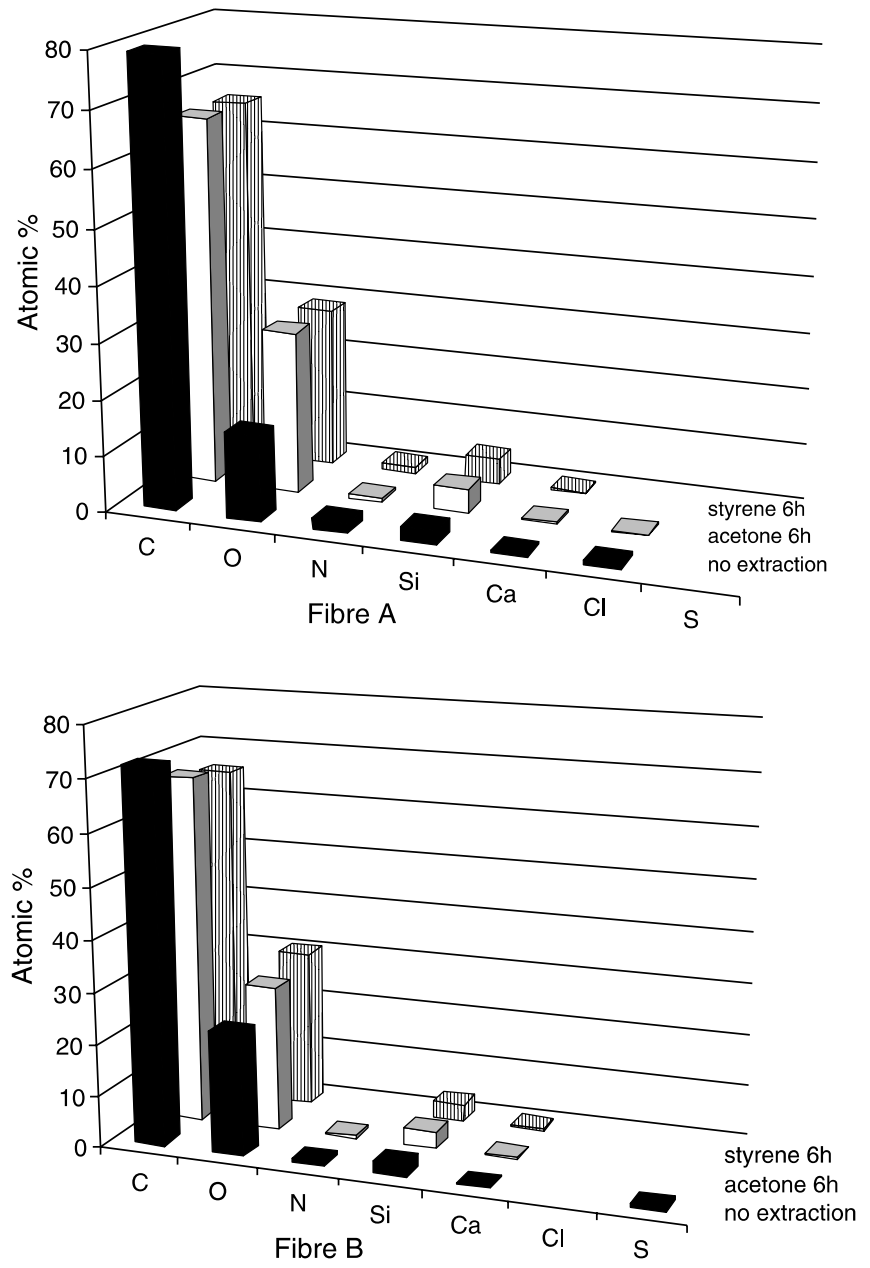

Fig. 4. Atomic \% versus extraction for fibres A and B ( before extraction, $\bigcirc$ acetone $6 \mathrm{~h}$, $\bigcirc$ styrene $6 \mathrm{~h}$ ).

surface energy $\gamma_{\mathrm{S}}$ shows that glass fibres and SMC paste can be considered as low surface energy solids. The dispersive component $\gamma_{\mathrm{S}}^{\mathrm{D}}$ is related to the ability for creating Van der Waals interfacial interactions at the solid surface. The polar component $\gamma_{\mathrm{S}}^{\mathrm{P}}$ is related to the ability for settling acid-base interfacial interactions at the solid surface.

It can be observed that the free surface energy is greater for the fibre A than for the fibre B and that the fibre A is more polar as Van der Waals interactions are more pronounced than the fibre B. This behaviour may influence the impregnation of the fibres by the SMC polyester resin and thus the fibre/matrix adhesion according to the conditions described in Section 1.

As the difference between the surface free energy of the fibre and of the resin is greater for the fibre A than for the fibre $\mathrm{B}$, it can be concluded that the wetting by the resin is better for the fibre A than for the fibre B. Moreover, as the polar and dispersive components of the fibre $\mathrm{B}$ are closer to those of the resin than those of the fibre A, it can be said that the fibre/SMC resin adhesion is better for the fibre B. 


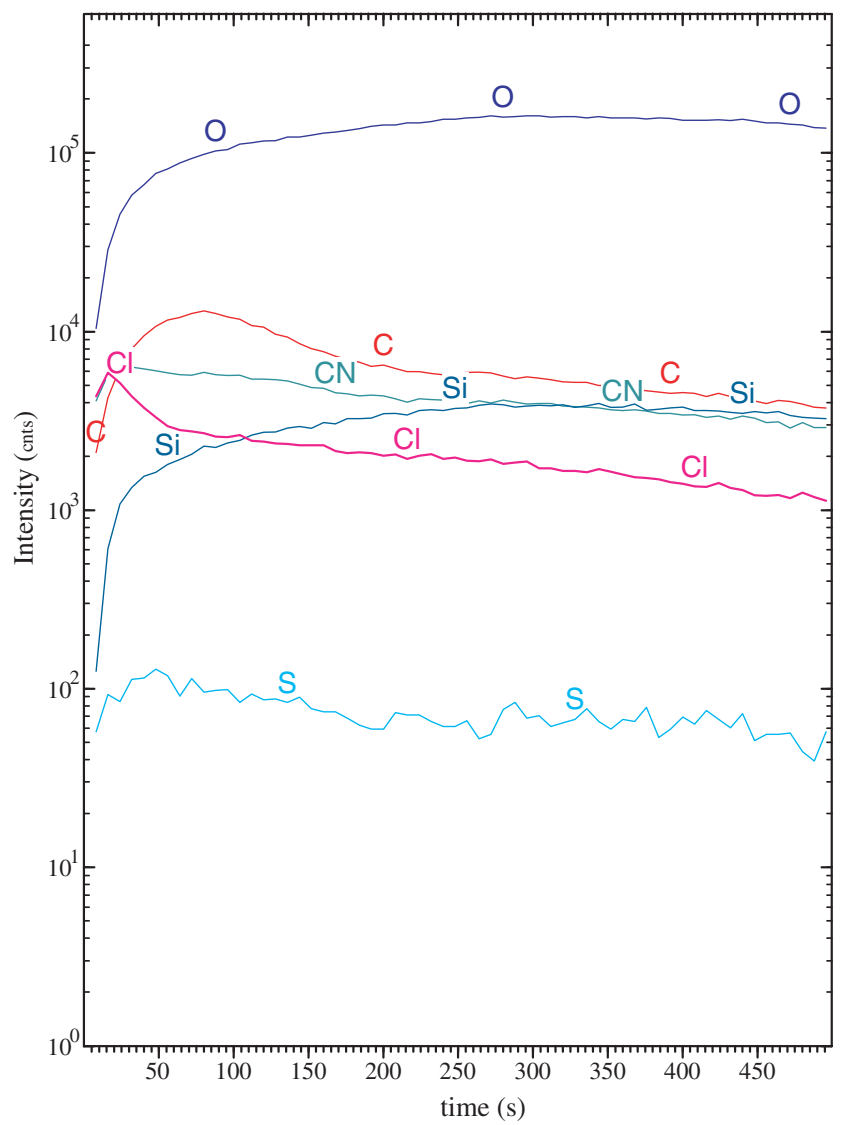

Fig. 5. Secondary ion depth profiles of the fibre A for a $100 \times 100 \mu \mathrm{m}^{2}$ area.

\section{Conclusions}

In the present work, the influence of two different fibre sizings on the impregnation level of the fibres by the SMC paste and on the surface quality has been analysed by studying the chemical functionality at the fibre surface and the surface free energy of the fibres. XPS analysis revealed the presence of chlorine and sulphur atoms, respectively, for the fibres A and B. By SSIMS, it has been possible to identify the chlorine and sulphur components as a dodecyltrimethylammonium chloride for the fibre A and a diethylsulphate for the fibre B. These components have been used as antistatic agents. FTIR spectra allow us to identify the film formers employed in the sizing formulations. For the fibre A, PVAc is used as a unique film former. For the fibre B, it appears that two types of film formers are applied on the fibre: a PVAc and a polyester. These results are supported by Pyrolysis/GC/MS analyses. The distributions of the chlorine and sulphur atoms were performed by DSIMS experiments. It can be assumed that there is a diffusion of both antistatic agents through out the sizing thickness in the direction of the fibre. This diffusion in only partial because XPS proved that $\mathrm{Cl}$ and $\mathrm{S}$ atoms were no more present on the fibres after extractions in acetone or styrene. Contact angle measurements allow us to study the wetting and adhesion behaviour between the

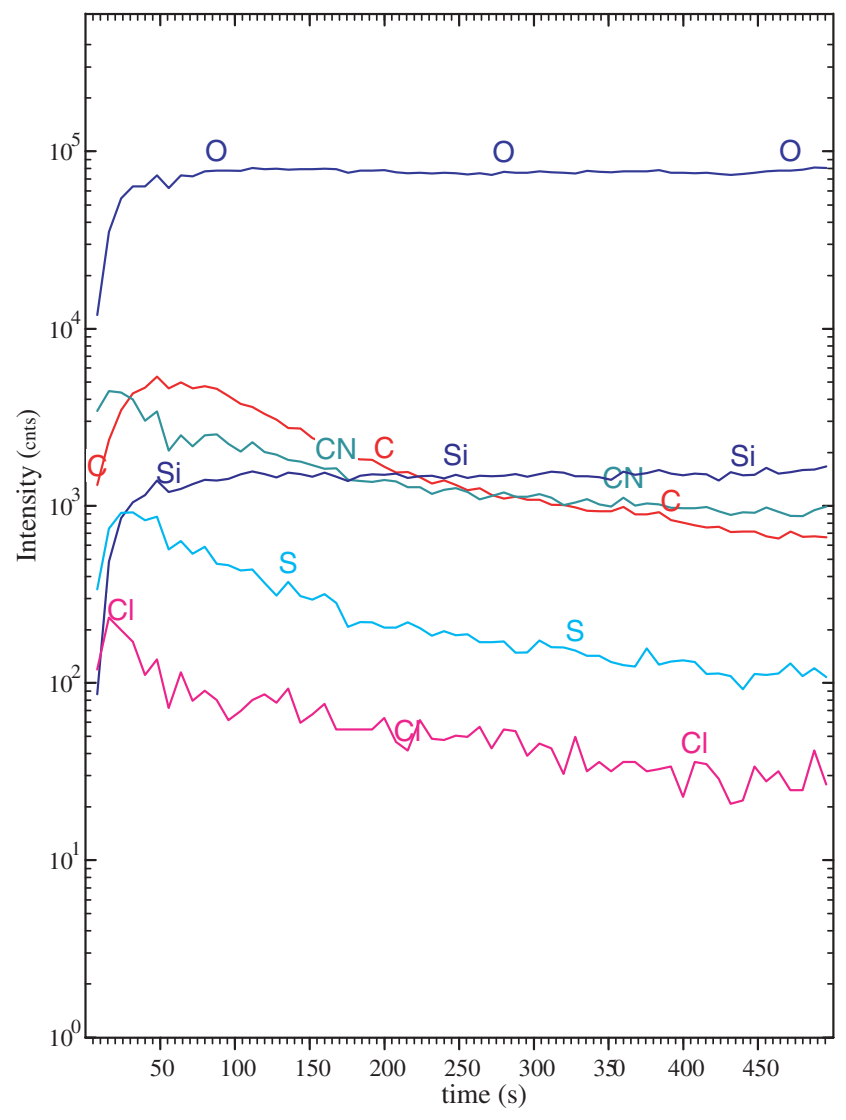

Fig. 6. Secondary ion depth profiles of the fibre B for a $100 \times 100 \mu \mathrm{m}^{2}$ area.

Table 7

Free surface energies and their polar and dispersive components

\begin{tabular}{lllc}
\hline & $\gamma_{\mathrm{S}}\left(\mathrm{mJ} / \mathrm{m}^{2}\right)$ & $\gamma_{\mathrm{S}}^{\mathrm{D}}\left(\mathrm{mJ} / \mathrm{m}^{2}\right)$ & $\gamma_{\mathrm{S}}^{\mathrm{P}}\left(\mathrm{mJ} / \mathrm{m}^{2}\right)$ \\
\hline Fibre A & $29.37 \pm 0.50$ & $12.29 \pm 1.73$ & $17.09 \pm 1.47$ \\
Fibre B & $26.57 \pm 1.05$ & $16.88 \pm 1.61$ & $9.68 \pm 2.64$ \\
SMC paste & $23.30 \pm 0.26$ & $22.10 \pm 0.32$ & $2.10 \pm 0.58$ \\
\hline
\end{tabular}

glass fibre and the SMC resin. Results have shown that the wetting properties are greater for the fibre $\mathrm{A}$ and that the fibre/SMC resin adhesion is better for the fibre B.

This preliminary study has shown that during the impregnation process, the natures of the antistatic agent and of the film former, the fibre wetting properties, the sizing solubility may play a major role on the impregnation level and may influence the surface quality of SMC moulded panels. But the correlations between the chemicals systems and the surface quality of the moulded SMC panels are not yet very clear.

However, a great advantage of this work is to consider real fibre sizings like those industrially used. Nevertheless, these materials for SMC applications have complex formulations, which involve a lot of parameters (components of the SMC paste, components of the fibre sizing and parameters of the compression moulding process). 
In a first step some correlations have been established between fibre parameters deduced from wetting experiments and different parameters of the surface quality of the moulded panels. It has been observed that the SMC panels moulded with the fibre A present a better Diffracto index but a greater number of defects than those moulded with the fibre B. So, it would be useful to introduce a new criterion to evaluate the surface quality of the moulded panels by a combination of the different characteristics.

Then the first conclusions obtained from this study performed on two different industrial fibres must be confirmed on more numerous fibres with varying parameters, such as the loss of ignition, the film former nature, the antistatic agent nature and the sizing deposit method. Moreover, other parameters should be considered for a more accurate analysis of the surface quality according to the fibre sizing that are the swelling and the dissolution rates of the sizing. The corresponding results will be detailed in a next paper.

\section{Acknowledgements}

This work was funded thanks to the French Ministry in charge of Industry (MINEFI) in the framework of the Eureka SURFAS project E 2373. The authors would also like to thank Saint Gobain Vetrotex International Co. (Chambéry, France) for providing samples and scientific advice.

\section{References}

[1] Ollive C. Critères de choix et avenir des SMC dans l'automobile. Composites 1991;3:145-52.

[2] Kim KT, Im YT. Experimental study on physical properties of compression molded SMC parts under plane strain condition. Compos Struct 1996;35:131-41.

[3] Arakawa K, Iwami K, Kimura K, Nomaguchi K. Factors affecting surface smoothness and the role of unsaturated polyester resin and glass fiber. J Reinf Plast Compos 1994;13(12):1100-15.

[4] Dupré A. Théorie mécanique de la chaleur. Paris, 1869; p. 393.

[5] Larson BK, Dzral LT. Glass fibre sizing/matrix interphase formation in liquid composite moulding: effects on fibre/matrix adhesion and mechanical properties. Composites 1994;25(7):711-21.

[6] Thomason JL. The interface region in glass fibre-reinforced epoxy resin composites: 3 . Characterization of fibre surface coatings and the interphase. Composites 1995;26(7):487-98.

[7] Thomason JL. The interface region in glass-reinforced epoxy resin composites: 1. Sample preparation, void content and interfacial strength. Composites 1995;26(7):467-75.

[8] Drown EK, Al Moussawi H, Dzral LT. Glass fiber 'sizings' and their role in fiber-matrix adhesion. J Adhes Sci Technol 1991;5(10):865-81.

[9] Palmese GR, Andersen OA, Karbhari VM. Effect of glass fiber sizing on the cure kinetics of vinyl-ester resins. Composites: Part A 1999;30: $11-8$.

[10] Gorowara RL, Kosik WE, McKnight SC, McCullough RL. Molecular characterization of glass fiber surface coatings for thermosetting polymer matrix/glass fiber composites. Composites: Part A 2001;32: 323-9.

[11] Bergeret A, Bozec MP, Quantin J-C, Crespy A. Study of interphase in glass fibre-reinforced poly (butylenes terephthalate) composites. Polym Compos 2004;25(1):12-25.
[12] Al Moussawi H, Drown EK, Dzral LT. The silane/sizing composite interphase. Polym Compos 1993;14(3):195-200.

[13] Gao P, Su KB, Ward Y, Weng LT. Effects of chemical composition and thermal stability of finishes on the compatibility between glass fiber and high melting temperature thermoplastics. Polym Compos 2000;21(2):312-21.

[14] Tsutsumi K, Ohsuga T. Surface characterization of modified glass fibers by inverse chromatography. Colloid Polym Sci 1990;268:38-44.

[15] Barraza HJ, Hwa MJ, Blakey K, O’Rear EA, Grady BP. Wetting behavior of elastomer-modified glass fibers. Langmuir 2001;17: 5288-96.

[16] Park SJ, Kim TJ. Studies on surface energetics of glass fabrics in an unsaturated polyester matrix system: effect of sizing treatment on glass fabrics. J Appl Polym Sci 2001;80:1439-45.

[17] Delfolie C, Depecker C, Lefebvre J-M. Interfacial phenomena in glass fibre reinforced polyester resin with low profile additives. Part I. Micromechanical evaluation by pull-out testing. J Mater Sci 1999; 34:481-95.

[18] Lam PWK. A comparative study of structure-property relationships in low-profile polyester matrices. Polym Eng Sci 1989;29(10):690-8.

[19] Huang YJ, Su CC. Effects of poly (vinyl acetate) and poly (methyl methacrylate) low-profile additives on the curing of unsaturated polyester resins. I. Curing kinetics by DSC and FTIR. J Appl Polym Sci 1995;55:305-22.

[20] Sun B, Yu TL. Effects of low-profiles additives on the curing reaction of unsaturated polyester resins. J Appl Polym Sci 1995;57:7-23.

[21] Huang YJ, Su CC. Effects of poly (vinyl acetate) and poly (methyl methacrylate) low-profile additives on the curing of unsaturated polyester resins: rheokinetics and morphological changes up to gelation. Polymer 1994;35(11):2397-410.

[22] Lee DS, Han CD. Effect of the chemical structure of low-profile additives on the curing behavior and chemorheology of unsaturated polyester resin. Polym Eng Sci 1987;27(13):964-75.

[23] Norme ISO 11667: 1997. Plastiques renforcés de fibre—Préimprégnés et compositions de moulage-Détermination des taux de résine, de fibre de renfort et de charge minérale-Méthodes par dissolution. 1997.

[24] Washburn EW. Phys Rev 1921;17:273.

[25] Jacobash HJ, Grundke K, Mäder E, Freitag KH, Panzer U. Application of the surface free energy concept in polymer processing. J Adhes Sci Technol 1992;6(12):1381-96.

[26] Tsutsumi K, Abe Y. Determination of dispersive and nondispersive components of the surface free energy of glass fibers. Colloid Polym Sci 1989;267:637-42.

[27] Owens DK, Wendt RC. Estimation of the surface free energy of polymers. J Appl Polym Sci 1969;13:1741-7.

[28] Gonzalez-Benito J, Baselga J, Aznar AJ. Microstructurtal and wettability study of surface pretreated glass fibres. J Mater Process Technol 1999;92-93:129-34.

[29] Thomason JL, Dwight DW. The use of XPS for characterisation of glass fibre coatings. Composites: Part A 1999;30:1401-13.

[30] Cherian JT, Castner DG. Using ESCA and SIMS in composites manufacturing. J Adv Mater 2000;32(1):28-33.

[31] Van Ooij WJ, Sabata A. In: Mittal KL, editor. Silane and other coupling agents. Utrecht, The Netherlands: VSP; 1992. p. 323.

[32] Moulder JF, Stickle WF, Sobol PE, Bomben KD. Hand book of Xray photoelectron spectroscopy. Eden Prairie, MN: Perkin-Elmer; 1992.

[33] Wesson SP, Jen JS, Nishioka GM. Acid-base characteristics of silanetreated E glass fiber surface. J Adhes Sci Technol 1992;6(1):151-69.

[34] Briggs D, Brown A, Vickerman JC. Handbook of SSIMS. New York: John Wiley and Sons; 1989.

[35] Sellitti C et al. Wettability of glass fibres with different sizings and their adhesion to unsaturated polyester matrices. J Mater Sci 1987; 22:3477-84. 